\title{
DIDÁTICA NO CURSO DE PÓS GRADUAÇAO; UMA CONTRIBUIÇÃO PARA A TRANSFORMAÇÃO DO FAZER DOCENTE NA UNIVERSIDADE.
}

\author{
(*) Lisete Diniz Ribas Casagrande \\ (**) Ana Maria Faleiros
}

\section{RESUMO}

Trata-se do relato de uma experiência desenvolvida em cursos de pósgraduação, sobre o processo de investigação e desenvolvimento de um programa para a disciplina Didática Geral. Descreve:

1) o objetivo - transformação do fazer docente na Universidade;

2) o conteŕdo - fundamentos teóricos do ensino superior e planejamento de ensino;

3) o método - "tomada de consciência e "micro-aulas".

4) a avaliação - diagnóstica, formativa e somativa.

\section{I - INTRODUÇÃO}

A disciplina Didática Geral foi introduzida nos cursos de Pós-Graduação da Faculdade de Ciências Agrárias de Jaboticabal, desde a época de sua criação em 1976, fazendo parte do elenco de domínio conexo dos cursos de Pós-Graduação em Agronomia (áreas de concentração em Produção Vegetal, Melhoramento Genético Vegetal e Entomologia Agrícola) e em Zootecnia (áreas de concentração em Produção Animal e Melhoramento Genético Animal).

E uma disciplina que possui carga horária de 120 horas/aulas, com 06 créditos, sendo 04 horas/aulas téricas semanais e 08 horas de leituras programadas, prática docente supervisionada e seminário.

Freqüentam a disciplina, os alunos regularmente matriculados nos cursos de mestrado e doutorado, em sua maioria profissionais formados em Ciências Agrárias (Agronomia, Zootecnia, Medicina Veterinária, Engenharia Florestal, Engenharia Agricola), os quais atuam como professores no ensino superior ou como extencionistas, trabalhando com agricultores e desempenhando o papel

(\%) Professora Doutora - Dep ${ }^{10}$ de Psicologia e Educaça da Faculdade de Filosofia, Ciencias e Letras de Ribeirto Preto - USP:

(1) Professora Assistente, Dep ${ }^{\text {to }}$ de Educaçáo da Faculdade de História, Direito e Serviço Social UNESP - Campus de Pranca. 
de educadores em instituições como (*)Cati e (**)Emater por exemplo. Nesta atividade, atuam com o objetivo de informar agricultores no sentido de que, assimilando novas técnicas agrícolas (de plantio, adubação, conservação do solo), terăo melhor produção agrícola. Esta ação provoca, conseqüentemente, mudança de atitudes, de mentalidade, de valores.

Ao tomar consciência deste fato, estes profissionais/alunos se assumem como educadores, o que tem ocasionado um grande interesse pela disciplina. $E$ também através da disciplina Didática Geral que entram em contato pela primeira vez, com temas mais gerais de formação humanística. (Filosofia, Psicologia, Sociologia).

A Didática Geral foi oferecida em 05 semestres de curso, durante uma década (de 1980 a 1990), tendo ocorrido nos seguintes periodos letivos: $2^{\natural}$ semestre de 1980; $2^{\prime \prime}$ semestre de $1985 ; 1^{\circ}$ semestre de $1986 ; 1^{\prime \prime}$ semestre de 1988 e $2^{\prime \prime}$ semestre de 1990, com uma média de 20 alunos por classe. Tem sido ministrada por duas professoras, que vem realizando uma praxis fundamentada no princípio de que o aluno é uma pessoa em processo de vir a ser e que consideraram que ensinar não é apenas transmitir conhecimento.

\section{II - A ESTRUTURA DA DISCIPLINA -}

Considerando as características da clientela que se matricula na disciplina, a expectativa dos professores era de que através da Didática Geral, se pudesse criar oportunidades para estimular os alunos - mestres a iniciarem uma reflexão sobre o seu próprio fazer docente; teriam como referência, um quadro teórico geral e um conteúdo diversificado, de modo a obterem uma visão mais ampla a respeito da Educação e do papel do educador, independente de sua área de atuação. Com isso, esperava-se que o aluno mestre fosse capaz de fundamentar e racionalizar suas decisões com relação ao processo ensino-aprendizagem, após assimilação de conceitos fundamentais, e mediante a vivência em sala de aula, de metodologia fundamentada na ação do aluno enquanto sujeito responsável pela sua propria aprendizagem.

Esperava-se que a vivência de situações de aprendizagem associadas a Uiferentes técnicas de ensino, fosse capaz de sensibilizar os alunos e produzir uma transformaçāo no modo de agir, assimilando uma postura de educador, capacitado a propor situações semelhantes a seus alunos.

No primeiro semestre em que foi ministrada (em 1980), houve uma preocupação em estruturar o conteudo, de modo a permitir que os alunos mestres,

() CATI - Coordenadoria de Assisténcia Técnica Integral, da Secretaria da Agricultura do Estado de
to Paulo. (*) EMATER - Empresa de Assistencia Técnica e Extensăo Rural, do Ministério da Agricultura. 
além de assimilarem conceitos fundamentais sobre o ensinar e o aprender, desenvolvessem a competência para utilizar técnicas de ensino apropriadas à natureza do conteúdo a ser aprendido e ds condiçōes do aprendiz. Foi utilizada a avaliação contínua, feita através de provas, após o estudo de cada unidade. Ao final da disciplina, baseadas em sugestōes de (*)Bordenave e Pereira, sugerimos que os alunos preenchessem a ficha de avaliação do curso e de auto avaliação, onde era solicitado que os mesmos se atribuíssem conceito entre $A$ e $D$. A experiência demonstrou que os alunos mestres se sentiram muito mais responsáveis ao fazerem a auto-avaliação.

Quando foi oferecida a disciplina em 1985, procurou-se fazer uma reformulação no conteúdo, na metodologia e principalmente na avaliação, considerando a necessidade de uma "praxis" que levasse em conta a avaliação contínua e qualitativa. Uma avaliação desta natureza não poderia fazer uso apenas de provas.

Portanto, considerou-se a necessidade de envolver os alunos, de modo que assumissem a responsabilidade da sua aprendizagem e que continuamente fornecessem "feed-back" aos professores.

Foram introduzidas mudanças significativas na prática de sala-de-aula. Além da apresentação do programa de ensino em sala-de-aula, os professores passaram a elaborar e distribuir aos alunos-mestres, um roteiro para cada aula, especificando o objetivo, o conterdo e os procedimentos que seriam utilizados. Introduziu-se a partir de então um procedimento para realizar a avaliação contínua, qualitativa, através do instrumento denominado Ficha de Anotação de Aula, que iremos descrever adiante. $A$ introdução deste modo de agir, contendo uma proposta mais dinâmica de ação na sala de aula, fez com que os professores assumissem a eliminação de provas escritas, neste curso de caráter essencialmente instrumental para futuros docentes de nivel superior. Considerou-se que a aquisição de atitudes e habilidades - objetivos fundamentais da disciplina Didática Geral - seriam melhor verificados por instrumentos de avaliação qualitativa, conforme apresentados adiante.

$O$ relato que se segue, refere-se à experiência desenvolvida em 1988 e 1990, e reflete o processo de investigação de um programa para a disciplina Didática Geral, que pudesse representar uma real contribuição para a transformação da atividade docente na Universidade.

\section{III - CONTEUDOO PROGRAMÁTICO DA DISCIPLINA:}

A disciplina Didática Geral em um curso de pós-graduação em Ciências Agrárias, na forma anteriormente descrita, teve um conteúdo bastante abrangente, mas que se justifica pelo fato de que os participantes - agrônomos, veterinários, zootecnistas, biólogos - não tiveram qualquer formação pedagógica. Deviam, pois, 
ser introduzidos nessa área de conhecimento, e levados a elaborar um conjunto de conceitos básicos integradores. Precisavam também familiarizar-se com a terminologia técnica e os procedimentos da pesquisa educacional - que leva à construção do conhecimento pedagógico - , bem como com a tecnologia de ensino mais recente.

Por essa razão, foram incluídos no programa (ANEXO 1), tópicos gerais de fundamentação teórica, relativos à base filosófica do ensino superior, às principais explicaçōes, interpretaçōes sobre a aprendizagem e o aprendiz (sobretudo o adolescente e o jovem adulto, clientela típica do ensino superior); e tópicos introdutórios de Sociologia da Educação, sobre as relações entre a escola e a sociedade. Toda essa parte da disciplina visa a contextualização do fazer docente, de modo a elaborar um quadro de referência que permita aos pós-graduandos a compreensão e racionalização de sua atividade.

A seguir, estuda-se a ação didática propriamente dita, incluindo o processo de planejamento de ensino, os componentes básicos do plano - objetivos, conteúdo, estratégias e avaliação - e seu interrelacionamento. Constatamos a grande expectativa dos pós-graduandos em relação às técnicas de ensino, e a tendência generalizada que apresentam de reproduzir os procedimentos didáticos, que lhes são familiares - aulas expositivas, basicamente. Por essa razão, e para proporcionar a esses colegas iniciantes no ensino superior, oportunidades de aproximação com uma prática docente transformadora, introduzimos uma atividade na disciplina, denominada "micro-aulas": consistem elas em situações simuladas de ensino, com o objetivo de estudar e testar, na prática, diferentes técnicas de ensino individualizado (instrução programada, estudo dirigido, módulos instrucionais), trabalho em grupos (diálogos sucessivos, grupos de verbalização e observação, grupos de oposição ou debate, painel integrado, seminários, conferências) e outras, como tempestade cerebral, desenhos em grupo, jogos didáticos, "workshop", práticas de campo, etc. que servem para obter a participação ativa dos alunos (Bordenave, 1982).

As micro-aulas, segundo o depoimento dos próprios alunos, cumprem o objetivo de vivenciar concretamente, alternativas metodologicas que, de outro modo, seriam apenas descritas pelos professores ou lidas em manuais de Didática, de modo pouco significativo, como mais um item do programa da disciplina. Destinamos às micro-aulas, cerca de um quarto das aulas disponíveis (4 aulas semanais, com duração de 4 horas), e gravamos as aulas em "video-tape", para que os alunos/mestres possam revê-las e analisá-las. No planejamento das micro-aulas, os alunos escolhem temas de sua própria área de especialização, e devem integrar os componentes essenciais do plano, já estudados - objetivos, conteúdo, estratégias e avaliação, verificando a coerência e a adequação das decisões tomadas. 


\section{IV - METODOLOGIA ADOTADA NA DISCIPLINA:}

Um aspecto muito importante, a nosso ver, em disciplina de pósgraduação da natureza de Didática Geral, é a metodologia adotada. Tratando-se de participantes que ja sao professores, e portanto trazem sua própria prática docente para confrontar com o quadro térico da disciplina, a postura e os procedimentos dos professores de Didática são vistos como "modelos", no sentido de exigir coerência entre o que eles dizem que deve ser feito no ensino, e o que eles realmente fazem em sala-de-aula. Daí a nossa preocupação em planejar e executar atividades de ensino-aprendizagem que se constituíssem em experiências pessoais significativas para os alunos, que, em si mesmas, representam possiveis formas de ação docente adaptáveis e aplicáveis às suas próprias disciplinas de graduação. Assim, a cada dia, são distribuídos "roteiros de aula", que antecipam, esquematicamente, as atividades a serem desenvolvidas por alunos e professores, levando o aluno a perceber a sequiência da aula, e o fato fundamental de que a sua participação ativa no trabalho de classe é que confere significado à aprendizagem. (ANEXO 2)

Como se percebe, são utilizados principalmente procedimentos de trabalho individual e em grupo, para o desenvolvimento do tema do dia, precedidos ou seguidos de aulas expositivas dialogadas, para introduzir ou sintetizar o assunto. Para enfatizar a "tomada de consciência" (Aebli, 1978) dos procedimentos utilizados pelos professores de Didática, solicita-se aos alunos, a cada aula, 0 preenchimento da Ficha de Anotação de Aula (ANEXO 3), contendo: um breve resumo dos itens principais tratados na aula anterior, uma descrição dos procedimentos utilizados pelos docentes, as conclusōes obtidas sobre o assunto estudado, e um comentário de análise crítica das experiências vividas na aula anterior. Nesse quadro, a Ficha de Anotação de Aula atende a uma dupla função:

a) permite recuperar o processo de ensino-aprendizagem ocorrido na aula, identificar as estratégias utilizadas e encarar essas alternativas metodológicas como "hipóteses de trabalho" a serem verificadas, e eventualmente adaptadas e aplicadas em seu próprio campo de atuação;

b) permite um acompanhamento individualizado de cada aluno, seu rendimento e suas possíveis dificuldades, ao mesmo tempo em que os professores recebem "feed-back" contínuo para o seu replanejamento.

\section{V - O PROCESSO dE AVALIAÇÃO dA DIDÁTICA GERAL}

A partir do que foi relatado, compreende-se que o processo de avaliação do rendimento no curso de Didática, para ser coerente com os objetivos, o conteúdo 
c a metodologia descritos, não poderia utilizar instrumentos convencionais, como provas escritas e exames. Assim, tentamos criar condiçōes para que os alunos (todos professores universitários, como já foi dito), vivenciassem uma avaliação contínua, essencialmente qualitativa e de tipo formativa, mais própria de uma atividade docente transformadora, em que o aluno é um ativo participante do processo, co-responsável pela sua própria aprendizagem. Nada mais lógico, aliás, tratando-se de adultos e profissionais qualificados, já no exercício da função docente em várias instituiçöes de ensino superior no país.

Foram, portanto, utilizados como instrumentos de avaliação formativa:

a) as fichas de anotação de aula a que nos referimos anteriormente, que informam aos alunos, sobre a evolução e sistematização de sua experiência, e áos professores, sobre o rendimento da classe e sobre o seu próprio desempenho;

b) os exercícios e tarefas realizados durante cada uma das aulas, corrigidos e comentados pelos professores;

c) o planejamento e a execução das micro-aulas.

A avaliação somativa utilizou dois elementos principais:

a) o trabalho final do curso, que consistia na elaboração de um plano de ensino detalhado da disciplina de graduação sob responsabilidade do participante; esse plano, corrigido e comentado pelos professores, foi devolvido aos alunos, para execução posterior nas respectivas instituiçōes de ensino superior;

b) uma ficha de avaliação somativa, composta de três partes:

1 - uma auto-avaliação do aluno, considerando o rendimento acadêmico (entendido como domínio do conteudo, compreensão dos conceitos estruturais, integração da experiência, mudança de atitudes, desenvolvimento de habilidades) e participação nas aulas (entendida como presença em classe, atuação nas atividades de classe, atenção e concentração no assunto, entrega de tarefas, pontualidade);

2 - uma avaliação na disciplina, em termos da contribuição que o curso representou a nível pessoal e profissional, e do desempenho dos professores, em termos do domínio do conteudo, planejamento e execução das aulas, interação com a classe;

3 - sugestões para replanejamento do curso, quanto aos objetivos, conteudo, estratégias e avaliação.

Os resultados obtidos com esse sistema de avaliação foram, a nosso ver, bastante positivos: a maioria dos alunos, cerca de $70 \%$, obteve conceito $\mathrm{A}$, e os demais, conceito B. Não ocorreram reprovações, e os alunos-mestres relatam 
grande envolvimento com a disciplina, utilização de carga horária maior que a exigida nas leituras e trabalhos do curso, decisão de modificar a programação de suas próprias disciplinas, desenvolvimento de maior consciência do papel de educador.

\section{VI - CONCLUSÃO:}

A partir do que foi relatado, concluímos que o objetivo proposto - de fazer da disciplina Didática Geral na pós-graduação, uma oportunidade de reflexão sobre a prática docente desenvolvida na Universidade, bem como de contribuir para uma transformação dessa prática -, esse objetivo foi atingido nas várias oportunidades que desde então se apresentaram às autoras, de desenvolver experiências semelhantes, com profissionais das mesmas Ciências Agrárias, e das Ciências da Saúde (Medicina, Odontologia, Enfermagem, Farmácia).

Como qualquer atividade educativa, a investigação desse programa da disciplina Didática Geral, é essencialmente dinâmica e se caracteriza pelo contínuo "vir a ser".

A experiência descrita não pode ser vista como algo pronto, acabado, mas como um momento da nossa história pessoal e profissional, extremamente relevante e significativo para nós, cujo relato, esperamos, poderá auxiliar outros professores na nossa tarefa comum.

\section{VII - BIBLIOGRAFIA CITADA:}

AEBLI, H. Didática psicológica: aplicação d didática da psicologia de Jean Piaget. Trad. de João Teodoro d'Olim Marote. $3^{a}$ edição. São Paulo, Edit. Nacional, 1978.

BORDENAVE, J. D. e PEREIRA, A. M. Estratégias de ensino-aprendizagem. 4" ed. Petrópolis, Edit. Vozes Ltda, 1982. 


\section{ANEXO I \\ - DidAtica geral -}

Número de Créditos: 5

Distribuição Semanal: 2-2

Número de Semanas: 15

Ementa: A disciplina visa proporcionar aos alunos, oportunidades de reflexão sobre a atividade docente no $3^{\circ} \mathrm{grau}$, elaborando um quadro de referência para a compreensão e sistematização da sua prática de ensino. $O$ programa a ser desenvolvido inclui elementos de fundamentação teórica da educação superior - introdução aos fundamentos filosóficos (formas e finalidades da educação, educação "bancária" e conscientizadora, postura do educador); fundamentos sociológicos (visão geral das relações entre escola e sociedade, sistema escolar brasileiro) e fundamentos psicológicos do ensino (noções de aprendizagem, motivação, interação professoraluno). E oferecida também uma orientação normativa do trabalho docente, abordando elementos de planejamento de ensino (objetivos, conteúdo programático, métodos e técnicas, instrumentos de avaliação do rendimento escolar), bem como uma preparação prática para um ensino inovador, através de micro-aulas (situaçôes simuladas em que os alunos utilizam e avaliam técnicas de ensino alternativas).

\section{Bibliografia Básica:}

ABREU, M. C. e Masetto, M. T. 1980. O Professor Universitário em Aula: práticas e principios teóricos. São Paulo, Cortez.

BORDENAVE, J. D. e Pereira, A. M. 1977. Estratégia de ensino-aprendizagem. Petrópolis, Editora Vozes Ltda.

CARVALHO, T. M. 1972. O processo didático. Rio de Janeiro, Fundação Getúlio Vargas.

RONCA, A. C. C. e Escobar, B. F. 1979. Técnicas Pedagógicas: domesticação ou desafio d participação? Petrópolis, Vozes.

SALDANHA, L. E. (org.) 1975. Planejamento e organização do ensino. Laboratório de Ensino Superior da Faculdade de Educação da UFRGS. Porto Alegre, Editora Globo.

TURRA, C. M. C. et al. 1975. Planejamento de ensino e avaliação. Porto Alegre, co-ediçāo PUC-EMMA. 


\section{ANEXO II \\ - didatica Geral .}

\section{Roteiro da 11`aula}

Data: 05 de novembro de 1990.

Assunto: Avaliação da aprendizagem - conceito e formas; avaliação em relação ao critério e em relação à norma; principais instrumentos de avaliação.

1) Retomada da aula anterior:

a) ficha de anotação de aulas - preenchimento

b) discussão do plano da aula anterior

2) "Brain-storm" sobre o vocábulo AVALIAÇÃO.

3) Painel integrado sobre o conceito e as principais formas de avaliação da aprendizagem escolar.

4) Discussão em comum para o levantamento dos pontos-chave do problema de avaliação da aprendizagem: o que $\epsilon$ avaliar? para que avaliar? como avaliar?

5) Solicitação de leitura: Cap. 7 - "Processo de Avaliação", do livro de Abreu e Masetto, O professor Universitário em Aula, pag. 91-109. 


\section{ANEXO III \\ - didática geral -}

Curso: P6s Graduagão

FICHA: ANOTAÇÃO DE AULA

Aluno:

Data:

Assunto: (breve resumo dos itens principais)

Procedimento: (descrição de como transcorreu a aula)

Conclusōes:

Comentário: (análise crítica da experiência vivida) 


\section{ANEXO IV \\ Avaliação Somativa: DIDÁTICA GERAL}

I) Auto - Avaliação: Conceito -

Você deverá se auto-avaliar, considerando os ítens abaixo:

1) Participação nas aulas - entendida como:

a) presença em classe

b) atuação nas atividades realizadas

c) atenção e concentração no assunto

d) entrega de tarefas

e) pontualidade

2) Rendimento acadêmico - entendido como:

a) domínio do conteúdo:

b) compreensão dos conceitos estruturais 
c) integração da experiência

d) mudança de atitudes

e) desenvolvimento de habilidade

II) Avaliação do Curso:

1) Aspecto em que o curso contribuiu:

a) a nível pessoal

b) a nivel profissional

2) Desempenho da professora:

a) domínio do conteúdo

b) planejamento e execução das aulas 
c) interação com a classe

3) Sugestōes para o próximo curso:

a) quanto aos objetivos:

b) quanto ao conteúdo:

c) quanto às estratégias:

d) quanto aos critérios e instrumentos de avaliação;

\section{ABSTRACT}

This paper describes the research and development process of a teaching plan for a post - graduate course called General Teaching Methods. The following items are presented: 1) the purpose - changing College ways of teaching; 2) the content - theoretical foundations of College teaching methods and teaching planning; 3) the ways of teaching - "awareness" and "micro-classes"; and 4) the evaluation-diagnostic, formative and summative. 
$-52-$ 